\title{
Práticas criativas contemporâneas: a teoria psicanalítica e suas contribuições para o processo de mediação empreendido pelo designer
}

\section{Contemporary creative practices: the psychoanalytic theory and its contributions to the mediation role undertaken by designers}

\author{
Luiza Fernandes Lootens Machado, Universidade de Brasília \\ lootens.luiza@gmail.com
}

Ana Mansur de Oliveira, Universidade de Brasília

anamansur@unb.br

\begin{abstract}
Resumo
Esta pesquisa tem por objetivo investigar contribuições da psicanálise para uma etapa específica de projetos de design: a etapa de conceituação. Esta etapa é compreendida como o momento projetual em que as questões simbólicas do projeto são analisadas em maior profundidade, a fim de se chegar a uma constelação conceitual que norteará o processo criativo. A pesquisa se dividiu em dois momentos. No primeiro, foi realizada uma análise de cinco metodologias projetuais utilizadas no design gráfico, buscando-se compreender como é proposto o processo de conceituação em cada uma. No segundo momento, foi efetuada uma investigação acerca de possíveis contribuições da psicanálise lacaniana para o processo de conceituação em design. Identificou-se que, apesar da reconhecida importância da questão simbólica no design, esta discussão ainda pode ser ampliada no que concerne à prática projetiva. Neste sentido, este estudo procura articular aspectos da escuta psicanalítica que podem oferecer contribuições ao manejo da dimensão simbólica em projetos de design.
\end{abstract}

Palavras-chave: Design, Psicanálise, Metodologia, Conceituação, Processo criativo.

\begin{abstract}
This research investigates contributions derived from the psychoanalytic theory to a specific stage in design projects: conceptualization. This stage refers to the moment in which designers analyze more carefully the symbolic aspects of the project, in order to reach a conceptual synthesis that will guide the creative process. The research was divided into two parts. In the first, an analysis of five graphic design methodologies was carried out, seeking to understand how the conceptualization process is thought out in each one. In the second part, an investigation was conducted on possible contributions of Lacan's psychoanalytic theory to the process of conceptualization in design. It was identified that, despite the importance of the symbolic dimension in design, this issue can still be further explored with regard to design practice. In this sense, this study seeks to articulate aspects of the psychoanalytic theory that can offer contributions to how the symbolic dimension can be handled in design projects.
\end{abstract}

Keywords: Design, Psychoanalysis, Methodology, Conceptualization, Creative process. 


\section{Introdução}

Esta pesquisa tem por objetivo investigar possíveis contribuições da teoria psicanalítica lacaniana para uma etapa específica de projetos de design: a etapa de conceituação. Entendendo a importância desta etapa no manejo cuidadoso das questões simbólicas do projeto, pretende-se impulsionar e ampliar as discussões contemporâneas nesse sentido. Assim, a pesquisa é de caráter essencialmente qualitativo, utilizando-se de revisão bibliográfica e buscando novas aproximações conceituais, advindas do cruzamento desses dois campos do conhecimento: design e psicanálise.

Ao se propor o desafio de expressar ideias, narrativas e afetos de forma visual, o design assume um papel estrutural de mediação simbólica do real (BECCARI, 2016). Ao mesmo tempo em que pode ser considerado reflexo das interpretações de mundo de um determinado grupo, ele também as engendra, atualiza e recria. Portanto, o processo de design implica em um alto grau de intencionalidade naquilo que se objetiva veicular simbolicamente em um projeto, ainda que parte dessa dinâmica esteja fora do controle absoluto do projetista. Neste sentido, percebe-se a importância de investigações acerca da etapa projetual em que as questões simbólicas do projeto são mais profundamente analisadas, etapa esta denominada como etapa de conceituação.

Ao sugerir que o design desempenha um papel de mediação do real, Beccari (2016) parte de uma perspectiva filosófica específica. Para o autor, há uma impossibilidade radical de se alcançar o real em si mesmo. O único contato possível com ele se daria por meio de articulações simbólicas. O ser humano, então, cria sentidos, narrativas e interpretações, que funcionam como anteparos na sua relação com o real. Ainda que a coisa interpretada não seja de fato interpretável, isso é tudo o que se tem: a interpretação. Pautado nesse raciocínio, Beccari (2016, p. 31) propõe um entendimento de design como "aquilo que articula leituras e narrativas do real, de modo a intervir nele e reestruturá-lo". O design seria, então, uma das dimensões da experiência humana a fazer essa mediação da nossa relação com o real. Para além de simplesmente veicular algumas ideias e afetos, o design faz mais. Ele sinaliza nossas leituras do real, sendo simultaneamente seu produto e produtor. Faz emergir sentido por meio da articulação espacial de todos os seus recursos de materialidade, como formas, tipografias, cores e texturas. Assim, impacta diretamente em como vemos e interagimos com o mundo.

Essa visão aponta para a importância da questão simbólica no design e, assim, não só reforça a necessidade de se projetar com intencionalidade, como também a centralidade da questão da conceituação nos projetos de design. É na conceituação em que se chega aos aspectos simbólicos que se deseja traduzir na forma final do projeto. Segundo Deleuze e Guattari (1992), conceitos são criados em função de problemas que se consideram mal colocados. Apesar de as colocações dos autores acerca da ideia de "conceito" se restringirem à atividade filosófica e de compreenderem a criação de conceitos como função exclusiva dos filósofos, algumas de suas elaborações podem ser frutíferas para a definição da conceituação em design.

Os autores identificam três componentes constitutivos da noção de conceito: (1) conceitos definem-se por seus componentes, distintos e inseparáveis, em relação consistente uns com os outros; (2) cada conceito remete a outros conceitos, tanto aqueles que o compõem, quanto aqueles aos quais se relaciona, em suas conexões presentes, em sua história e em seu devir; e (3) conceitos são o ponto de condensação de seus componentes. Em outras palavras, os autores entendem 
"conceito" como o ponto de síntese entre componentes distintos, porém inseparáveis, cada um dos quais imprescindíveis para a definição do conceito em questão. Ademais, eles são produto de atividade cognitiva e estão em relação infinita com outros conceitos.

De maneira análoga, podemos pensar os conceitos em design como sínteses que tocam na essência dos aspectos simbólicos do projeto, sendo produtos de reflexão extensiva, desenvolvida com base nos dados coletados nos momentos iniciais de briefing e definição do problema. Outro entendimento advindo de Deleuze e Guattari (1992) que pode ser útil à questão da conceituação no design é a de que conceitos são criados como ferramentas para dar conta de problemas até então mal colocados. A forma como o problema está sendo posto pode ser justamente aquilo que está impedindo sua solução. Assim, a gênese de novos conceitos é entendida como uma forma de recolocar o problema e, assim, potencialmente dissolvê-lo. No design, pode-se pensar os momentos iniciais do projeto - desde a circunscrição da situação de projeto até a coleta e análise de dados primários - como o problema "mal colocado", uma vez que ainda não possui solução evidente. A etapa de conceituação viria, então, como o momento de se aprofundar no problema, buscando conseguir recolocá-lo, por meio da articulação de conceitos que possibilitem sua resolução.

Dessa forma, em resumo, a etapa de conceituação, sob a qual esta pesquisa se debruça, é entendida aqui como um estágio projetual que se situa entre a etapa inicial de identificação, pesquisa e análise do problema e a etapa de criação em si. Configura-se como o momento do projeto em que são unidas todas as informações e análises da etapa inicial e, com esta base, são desenvolvidas reflexões mais elaboradas, a fim de se alcançar uma síntese conceitual que servirá de guia do processo, como aquilo que se deseja traduzir na forma final do projeto. Dessa maneira, garante-se maior intencionalidade com relação aos aspectos simbólicos do projeto.

Essa relação íntima entre o design, a questão simbólica e a noção de intencionalidade já é indicada na própria origem etimológica da palavra “design”. Segundo Moura (2019), o termo é a junção de dois radicais latinos: de e signum. O primeiro, de, trata-se de uma preposição que denota proveniência e, assim, remete à mudança de um estado a outro e à noção de design enquanto ação transformadora. O segundo, signum, trata-se do substantivo "signo", unidade básica da comunicação. A união dos dois indica, portanto, uma nova realidade significativa, fruto desta ação transformadora praticada pelo design. Assim, percebe-se que, já na origem da palavra "design", estava explicitado que aquilo com o que se está operando na prática é justamente a dimensão simbólica.

Outra leitura acerca da etimologia de "design" refere-se a sua aproximação com a palavra "desígnio". Ao dissecar a palavra "design" em seus múltiplos significados em diversos idiomas, Zimmermann (1998) estabelece um paralelo entre essas duas palavras, "design" e "desígnio". Esse paralelo aponta para a aproximação de "design" com o sentido de propósito e de intenção, assim como com uma ideia ou um esquema que possa ser realizado. Portanto, a noção de processo também está presente na etimologia de "design".

Considerando todas as questões levantadas até aqui acerca do papel do design na mediação do real, por meio de articulações simbólicas, fica clara a importância de se investigar os momentos na prática projetiva em que são discutidas e delimitadas questões desta ordem, sintetizados no 
termo "etapa de conceituação". Esse tipo de estudo mostra-se essencial no momento sóciohistórico em que vivemos, efervescente e plural, que pede por investigações cada vez mais profundas, e no qual é arriscado objetivar e mecanizar as práticas projetivas.

Portanto, esta pesquisa tem por intuito impulsionar as discussões contemporâneas acerca da etapa de conceituação, buscando possíveis contribuições ao tópico em um outro campo de conhecimento, a psicanálise lacaniana. Uma vez que Lacan entende o inconsciente como intrinsecamente articulado ao simbólico, o autor destina muitos de seus esforços teóricos ao desenvolvimento de elaborações acerca do registro do simbólico e de como se pode operar com ele na clínica psicanalítica. Esta é, portanto, a razão para se buscar tais contribuições neste campo específico: a relação íntima da psicanálise lacaniana com a questão da dimensão simbólica.

Em termos metodológicos, a pesquisa dividiu-se em dois momentos. No primeiro, foi feito um levantamento bibliográfico sobre a questão da conceituação no design, com o intuito de mapear a produção já existente. O levantamento tem foco em algumas metodologias projetuais consagradas do design gráfico, buscando fazer uma análise a respeito da conceituação nos processos propostos pelos autores. No segundo momento, foi feita uma investigação acerca de possíveis contribuições da psicanálise lacaniana para a análise do processo de conceituação em design. Vale destacar que as aproximações propostas por esta pesquisa entre psicanálise e processos em design são apresentadas não tanto com o intuito de virem a se tornar eventuais encaminhamentos metodológicos, e sim com o intuito de potencializar discussões contemporâneas a respeito deste tema.

\section{Metodologias em design e conceituação}

Antes de buscar possíveis contribuições ao processo de conceituação em um outro campo do conhecimento, faz-se essencial compreender a conjuntura atual das discussões acerca deste tema dentro do próprio campo do design. Portanto, o primeiro momento da pesquisa caracterizou-se por um levantamento bibliográfico a respeito da prática de conceituação no design.

Identificou-se que a literatura relacionada a este tópico específico ainda se encontra incipiente. Os autores que o abordam tendem a partir de uma entre duas perspectivas específicas: a perspectiva do design conceitual e a perspectiva metodológica. De um lado, no caso dos autores que tecem suas elaborações partindo do design conceitual, as diretrizes ficam restritas a esta abordagem específica. Do outro, no caso dos autores que tocam em aspectos da conceituação em suas propostas metodológicas, as elaborações sobre esta etapa ainda se encontram superficiais. Assim, o cenário geral da produção teórica em design a respeito do tópico de conceituação ainda é de escassez, o que pode simultaneamente ser efeito e causa de uma prática pouco atenta a esta questão. Ferreira (2010, p. 25), em sua tese de mestrado sobre design conceitual na era pósindustrial, defende que "a prática conceitual em design é continuamente ignorada, marginalizada e confinada ao campo da arte."

Dessa forma, com o intuito de aprofundar o entendimento a respeito da prática de conceituação no design, foi feita uma análise de cinco metodologias projetuais voltadas à identidade visual, escolha que foi realizada para a criação de uma linha de investigação mais objetiva. Assim, os 
autores estudados foram: Peón (2003), Henrion (1991), Costa (1989), Ambrose e Harris (2011) e Frascara (2010). Nesta análise, buscou-se compreender o lugar da conceituação nos processos metodológicos propostos por cada autor. Uma vez que somente uma das metodologias apresenta uma etapa projetual de fato denominada Conceituação, buscou-se também, nas demais propostas metodológicas, por indicações de proximidade entre aquilo que o autor estaria propondo para determinada etapa e aquilo que entendemos como sendo constitutivo da conceituação. Foram consideradas atividades próprias da conceituação aquelas que envolvem o aprofundamento do briefing em nível simbólico, assim como a síntese e a seleção de guias simbólicos do projeto.

O interesse pela questão metodológica no design se deu junto às transformações socioeconômicas das quais o mundo foi palco no pós Segunda Guerra. O aumento na quantidade e complexidade das demandas destinadas aos designers, sobretudo a partir da década de 60 , foi responsável por um crescente esforço em busca de uma sistematização dos processos em design (BÜRDEK, 2010). No contexto atual, as demandas seguem multiplicando-se em quantidade e complexidade, bem como a pressão por "mais/melhor/mais rápido" torna-se cada vez mais intensa. Dessa forma, a adesão a métodos de projeto robustos e abrangentes, com o intuito de otimização da prática, é por vezes indispensável. Este cenário evidencia a atualidade e a relevância da questão metodológica no design, apontando também para a importância de metodologias que abordem a questão da conceituação com maior profundidade.

Nas cinco perspectivas metodológicas analisadas nesta pesquisa (PEÓN, 2003; HENRION, 1991; COSTA, 1989; AMBROSE; HARRIS, 2011; e FRASCARA, 2010), apesar de os autores proporem etapas diferentes, pode-se dizer em linhas gerais que todos fazem referência a dois momentos imprescindíveis do processo projetual: a etapa inicial de identificação, pesquisa e análise do problema, seguida da etapa de criação. Somente uma destas abordagens, a de Henrion (1991), apresenta de fato uma etapa nomeada Conceituação, que é situada entre as etapas iniciais de Análise e Especificação e a etapa de Desenvolvimento. No entanto, ainda que as demais metodologias não destinem um momento específico para a conceituação, elas eventualmente tangenciam aspectos que se aproximam das reflexões características desta etapa.

Este é o caso da metodologia de Peón (2003) para a criação de sistemas de identidade visual (SIV). A autora propõe três etapas: (1) Problematização, em que são definidos os requisitos e restrições do projeto; (2) Concepção, em que se cria uma solução para o projeto; e (3) Especificação, em que se desenvolvem as especificações técnicas que orientam a implantação do SIV. Segundo a autora, um dos objetivos da etapa de Problematização seria a definição de conceitos a serem veiculados pelo SIV, para serem agregados à imagem corporativa. Estes conceitos seriam então inventariados pelos projetistas, hierarquizando-os de acordo com a importância para a imagem da organização. Na etapa seguinte, de Concepção, a autora reforça a necessidade de consolidação da definição dos conceitos a serem veiculados. Neste momento, ela cita exemplos de conceitos, como: simplicidade, sofisticação, tradição etc. Percebe-se, assim, que a autora identifica a necessidade de conceituação, mas não entra nos pormenores de como manejar as informações previamente coletadas, para então chegar nessas sínteses conceituais.

Nas metodologias analisadas, identifica-se uma hibridização entre o momento de conceituação e outros momentos do projeto, como o de definição do problema e o de criação. Quando os autores falam de aspectos projetuais que se aproximam da tarefa de conceituação, 
no geral, trata-se de comentários relativamente breves em etapas cujo foco central não é o de conceituação especificamente. Essa hibridização se encontra até em Henrion (1991). Apesar de o autor elencar a conceituação como uma das etapas de sua abordagem metodológica, a descrição da etapa inclui aspectos de criação. Sua abordagem metodológica divide-se em sete etapas: (1) Análise; (2) Especificações; (3) Conceituação; (4) Desenvolvimento; (5) Bases do design; (6) Motivação; (7) Execução. O autor descreve os objetivos da terceira etapa, de Conceituação, como sendo a criação dos conceitos e dos elementos básicos de design: símbolos, logotipos e cores. Assim, percebe-se a hibridização entre o momento de conceituação e o de criação.

No caso de Ambrose e Harris (2011), os comentários que se aproximam de uma tarefa de conceituação são localizados na primeira etapa projetiva. Os autores propõem um esquema metodológico de sete etapas: (1) Definição do problema; (2) Pesquisa - coleta de informações; (3) Geração de ideias; (4) Teste de protótipo; (5) Seleção; (6) Implementação; e (7) Aprendizado. Na primeira etapa, de Definição do problema, os autores destacam a necessidade de interpretação do briefing e de aprofundamento nos significados dos conceitos-chave, como forma de garantir que cliente e designer tenham as mesmas expectativas sobre o trabalho.

À medida que se desenvolve uma relação de trabalho entre o designer e o cliente, um maior entendimento sobre o que significam os termos-chave é obtido. O designer precisa interpretar o briefing e definir o que significam palavras como "estiloso" e "bacana" - garantindo que ambas as partes compartilhem as mesmas expectativas. (AMBROSE; HARRIS, 2011, p.13, grifo nosso)

Esse aprofundamento no significado dos conceitos-chave, proposto por Ambrose e Harris (2011), é parte essencial de uma conceituação bem realizada, não só para alinhar expectativas entre designer e cliente, mas também para que o projetista possa desenvolver um trabalho mais embasado, substancial e eficaz. Percebe-se, assim, uma aproximação entre as tarefas propostas nesta etapa inicial e a tarefa de conceituação. Os autores ainda colocam que um dos objetivos desta etapa de Definição do problema seria o estabelecimento das ideias e valores gerais que o projeto deve transmitir ao público-alvo. Considerando que este é o objetivo-fim da conceituação, vê-se mais uma vez, que os autores unem os momentos de definição do problema com o de conceituação.

Nas metodologias de Costa (1989) e Frascara (2010), essa hibridização é menos evidente, pois os autores tocam em menos aspectos associados à tarefa de conceituação. Ainda assim, pode-se argumentar que a hibridização ainda aparece em algum grau. Na abordagem de Costa (1989) para a criação de sistemas de identidade visual, o autor propõe três etapas, as quais, por sua vez, dividem-se em subetapas: (1) Informação e planejamento; (2) Desenho gráfico - criação e desenvolvimento; e (3) Implantação. O momento de sua abordagem que mais se aproxima da tarefa de conceituação é na etapa de Informação e planejamento, quando o autor evidencia a necessidade do estabelecimento dos objetivos do programa de identidade visual e da definição dos atributos da personalidade da organização, destacando que esta tarefa demanda a interpretação da identidade da empresa, que será traduzida em palavras e depois em imagem. Esse caráter interpretativo dado pelo autor à tarefa de definição da identidade da organização aponta para uma aproximação deste ponto com a etapa de conceituação, uma vez que envolve algum grau de 
reflexão e manejo das informações coletadas. No entanto, esta tarefa aparece em uma etapa com uma série de outras tarefas e objetivos, indicando mais uma vez a hibridização mencionada.

Já Frascara (2010) propõe uma abordagem de 10 etapas: (1) Solicitação do projeto pelo cliente; (2) Coleta de informações; (3) Análise, interpretação e organização das informações; (4) Definição de objetivos; (5) Especificações do problema; (6) Geração de alternativas; (7) Apresentação ao cliente; (8) Organização da produção; (9) Implementação; e (10) Avaliação. Na etapa de Definição de objetivos, o autor cita brevemente a necessidade de definição da mensagem, mas não se detém muito neste tópico. Outros objetivos incluem as seguintes definições: objetivos gerais do projeto; o que a peça deve conseguir fazer; o canal de comunicação; o alcance do projeto e o contexto em que se insere. Assim, mais uma vez, vê-se a fusão entre tarefas próprias da conceituação e as demais estabelecidas no projeto.

A hibridização entre etapas é parte natural do processo de criação. Poucos são os projetos que seguem um processo linear e com etapas bem definidas. No entanto, o fato de a conceituação raramente ser considerada uma etapa específica nas metodologias analisadas é algo a ser considerado. As sistematizações metodológicas privilegiadas em cada época são bons indicativos da disposição geral da relação dos projetistas com sua prática. Indicam aquilo que se prioriza e que se considera essencial em um processo de criação. Assim, é digno de nota que o manejo dos aspectos simbólicos do projeto não aparece com frequência enquanto uma etapa ou subetapa específica nas propostas metodológicas atuais. A prática conceitual aparenta receber pouco destaque nas sistematizações de metodologia de projeto em design, arriscando-se a ficar subsumida entre outros momentos do projeto. Vale salientar que a conceituação não é resultado de uma simples síntese objetiva das informações coletadas nos momentos iniciais do projeto. Demanda interpretação e reflexão, e inevitavelmente convoca o projetista a se colocar ativamente nesse processo.

É importante destacar, ainda, que, em qualquer sistematização metodológica, há perdas. Ao se elencar determinadas etapas específicas de projeto, outras, às vezes sequer conscientes ou concebidas, passam indiferenciadas. Ao se formular uma metodologia que busca abranger toda uma área de atuação, há risco de perdas. Ao se definir um caminho específico, enquanto se apaga toda a dimensão de possíveis caminhos alternativos, há mais uma vez esse risco. A sistematização, ainda que grande aliada da prática, não vem sem riscos. Assim, ao se apontar para o fato de que as metodologias analisadas não trazem a conceituação como uma etapa à parte das demais, não se tem, como pano de fundo, uma expectativa irreal de que elas sejam exaustivas e capazes de dar conta de todos os desafios de um projeto de design. Deseja-se meramente colocar que, justamente pela falibilidade de tentativas de sistematização, reflexões contínuas e sempre atualizadas são imperativas neste âmbito.

Dessa forma, considerando a visão de design enquanto mediador da nossa relação com o real, via articulações simbólicas (BECCARI, 2016), argumenta-se que a prática em design poderia se beneficiar de mais investigações em torno da questão da conceituação e dos aspectos simbólicos do projeto, ponto com o qual esta pesquisa busca contribuir. A seguir, são discutidas algumas possíveis contribuições advindas da psicanálise, campo do conhecimento que tem a dimensão simbólica como fio condutor da sua prática. 


\section{E a psicanálise com isso?}

Antes de iniciar a etapa de criação propriamente dita, o designer trabalha com um arcabouço de informações originadas de análises, pesquisas de mercado e investigações sobre o públicoalvo. Se ele desejar manejar essas informações a fim de conseguir desenvolver reflexões que tenham o potencial de transcender a primeira camada de sentidos e chegar a conceitos sucintos, bem elaborados e condizentes com a realidade do projeto, de que forma ele pode fazê-lo? E como a psicanálise pode contribuir com os entendimentos desse momento projetual?

De maneira análoga ao designer nesta etapa, o psicanalista também trabalha com um arcabouço discursivo diante de si, neste caso vindo do analisando. Dentre outras várias facetas de seu trabalho, uma delas envolve a escansão do discurso do analisando, a fim de promover aberturas, que possibilitem o surgimento de novas narrativas. Para tanto, o psicanalista trabalha com uma escuta ajustada (SOLER, 2012). Essa escuta possibilita que o profissional se desprenda das significações do discurso e, assim, dê espaço para que o inconsciente seja escutado. No entendimento psicanalítico, uma cadeia discursiva sempre esconde uma outra, e isto é o que nos possibilita dizer sem formular (SOLER, 2012). Se, do lado do psicanalista, esse ajuste de escuta tem por objetivo permitir que o inconsciente advenha, do lado do designer, este não é necessariamente um objetivo concernente a sua prática. Não obstante, o designer pode se beneficiar dessa postura geral de escuta desprendida das significações do discurso.

Uma das premissas bases dessa escuta é o ponto de interrogação que se coloca entre os significantes e os significados. Esta elucidação talvez tenha sido uma das contribuições mais marcantes de Lacan para a psicanálise. O autor parte do conceito de signo linguístico de Saussure, e o subverte (LONGO, 2006). Para Saussure, o signo constitui-se como uma entidade psíquica de dois lados: o significado (conceito) e o significante (imagem acústica). Ele os dispõe como um conjunto inseparável, cuja relação necessariamente leva à significação. Em Lacan, contudo, quebra-se esta unidade do signo, ao se admitir o equívoco que a função simbólica comporta (LONGO, 2006). O significante, aqui, não aponta diretamente para o significado, senão para uma cadeia de outros significantes.

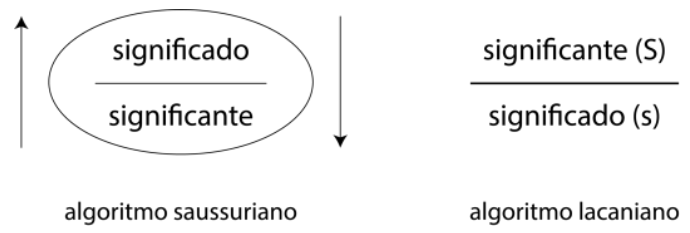

Figura 1: Esquema de signo linguístico em Saussure e Lacan. Fonte: Longo (2006, p. 44/45)

Essa forma de olhar para o signo linguístico leva a uma postura geral de entendimento de que se fala muito mais do que se diz e se escuta muito menos do que se fala. Se essa postura é então aplicada à etapa de conceituação de projetos de design, permite-se uma primeira abertura de discurso. Ela coloca um ponto de interrogação diante de qualquer significante-chave que vá surgindo nos momentos iniciais do projeto. Assim, as informações coletadas em uma primeira instância não significam uma determinação de caminho a ser seguido, senão um ponto de partida de investigação. Em um projeto de identidade visual, por exemplo, ao receber um pedido por uma 
marca "dinâmica", o designer não precisa instantaneamente convertê-lo em formas fluidas, diagonalizadas e circulares, indicando movimento. Pode, diferentemente, propor-se a investigar o que significa dinamicidade para aquele cliente, de que forma esta qualidade integra a realidade da marca, de que forma se aproxima ou se distancia do entendimento convencional do termo, de que forma se relaciona com os outros significantes-chaves daquele projeto etc.

Ao mesmo tempo em que o entendimento lacaniano de significante aponta a priori para um esvaziamento de significado, indica também, por consequência, a necessidade de fazer estes significantes deslizarem, naquilo que Lacan chamou de "deslizamento metonímico" (LONGO, 2006). Aquilo que não se alcança com um único significante, o sentido final, busca-se eternamente com o deslizamento deste em uma cadeia de outros significantes. Segundo este autor, no entanto, é impossível tudo dizer. A verdade completa jamais é alcançada, pois o nosso próprio anteparo de relação com o mundo, a linguagem, ao mesmo tempo que nos funda enquanto sujeitos, também instaura a falta. E, no entanto, ainda assim, deve-se falar, deve-se tentar. Ao fazer um significante deslizar, tem-se a possibilidade de melhor elaborar e narrativizar aquilo que ele circunscreve, mesmo que nunca se logre chegar ao âmago.

Uma outra subversão de Lacan no que diz respeito à relação entre significante e significado trazida por Saussure refere-se a um engrossamento da barra que separa um do outro no esquema saussuriano, o que indicaria uma resistência à significação. $\mathrm{O}$ falante desliza de significante em significante, sem entender o que de fato está falando. O atravessamento da barra, isto é, o instante em que se alcança algum sentido, ocorreria somente em raros momentos, mas acontece porventura. Eventualmente, atinge-se algum sentido, toca-se em alguma verdade. Este momento foi chamado pelo autor de "ponto de basta", uma pausa no deslizamento contínuo entre significantes, ou também um "congelamento metafórico" (LONGO, 2006). É claro, contudo, que se trata de alcançar somente uma verdade parcial, uma verdade dita pela metade. Logo em seguida a esse regozijo do encontro com a verdade parcial, volta-se ao deslizamento metonímico. O processo acontece, então, como o fechamento e a reabertura de gestalts, de forma serial.

Em um processo psicanalítico, a serialidade desse processo é a tônica. Em um projeto de design, no entanto, já poderíamos nos dar por satisfeitos se alcançássemos um ponto de basta. Assim, o caminho de elaboração do conceito passaria por colocar significantes-chave a deslizar, em uma tentativa de elaborá-los e inseri-los em uma narrativa maior, que englobaria os demais aspectos do projeto. Nesse esforço de elaboração, aconteceria então um momento de ponto de basta, em que determinados conceitos se mostrariam efetivos em sintetizar, de forma mais substancial, aquilo que se intenciona imprimir enquanto sentido, quando do encontro da materialidade do design com o mundo.

Direcionamentos mais práticos acerca de como possibilitar a abertura do discurso e dar espaço ao inconsciente podem vir da regra fundamental da psicanálise: a associação livre do lado do analisando, e a sua contrapartida do lado do analista, a atenção flutuante. Estas são técnicas analíticas utilizadas com o propósito de fazer advir lembranças, pensamentos e impulsos que até então se mantiveram fora da consciência (FREUD, 1904 [1905]/2020).

A proposta da associação livre é a de encorajar o paciente a falar livremente, sem se apegar às limitações lógicas de uma conversa típica. Se em vias de falar de certo assunto, outro assunto 
diferente lhe ocorrer, o paciente é encorajado a passar a este novo tópico. Ele é instruído a seguir o fluxo determinado por sua psiquê, e não pela lógica, mesmo que eventualmente julgue o que lhe vêm à mente como não importante ou embaraçoso. A teoria de Freud é de que os sintomas ocupam o lugar de processos psíquicos que foram reprimidos, e certas ocorrências involuntárias do discurso em associação livre do paciente funcionam como sinais destas formações psíquicas recalcadas (FREUD, 1904 [1905]/2020). Exemplos dessas ocorrências involuntárias seriam: esquecimentos, atos falhos, esfacelamentos de relações causais, etc. Assim, ao trazer essas formações psíquicas recalcadas de volta à consciência, possibilita-se o escoamento de afetos e, assim, a suspensão do sintoma.

Em um projeto de design, uma vez que todas as informações iniciais tenham sido coletadas e analisadas, e os objetivos, requisitos e restrições do projeto tenham sido definidos, o designer pode se beneficiar de um procedimento análogo ao da associação livre para dialogar com estas informações. O intuito deste momento projetual é o de estabelecer uma relação aprofundada com as diretrizes da situação inicial de projeto, relacionando-as de forma a alcançar as sínteses simbólicas que se tentará traduzir na forma final do projeto. Ao se propor a elaborar todas estas questões em associação livre, encorajando-se a mergulhar nelas e, momentaneamente, perdendo de vista os objetivos finais desta prática, o designer conseguirá ampliar a reflexão e em sequência o discurso neste momento de conceituação. Assim, diminui o risco de as proposições simbólicas e materiais do projeto se tornarem excessivamente literais ou superficiais.

Da mesma forma que a prática projetiva pode se beneficiar de uma aproximação com a associação livre, ela também pode se beneficiar da tarefa do analista de manter-se em atenção flutuante. Essa escuta em atenção flutuante é praticada pelo analista, com o intuito de que as ocorrências involuntárias do discurso do analisando possam, de fato, ser escutadas. Trata-se de uma técnica analítica de ajuste da escuta, em que se intenta desprender-se das significações do discurso, para, assim, deixar o inconsciente se fazer ouvir. Freud (1912/2020) destacava que o ponto central da atenção flutuante seria o de se manter ouvindo tudo o que o paciente diz, sem se preocupar com lembrar de algo e sem se apegar a certas partes do discurso. Assim que o analista retém a atenção em determinado ponto do discurso do paciente, ele passa a selecionar e fixar partes deste material, enquanto elimina outras. Nessa seleção, acaba por somente confirmar suas expectativas e inclinações e, por isso, corre o risco de não encontrar nada diferente do que já acreditava saber, ou seja, corre o risco de não escutar nada de novo.

A atenção flutuante de Freud consistia em se desprender, diria de bom grado em 'se distrair', das significações do discurso; é uma suspensão, como um 'não acreditar nisso' metódico, para colocar no mesmo plano todos os elementos verbais ou figurativos, até o menor detalhe aparentemente insignificante, a partir do qual o outro texto vai se isolar. (SOLER, 2020, p. 48)

Em um projeto de design, a atenção flutuante, assim como a associação livre, pode funcionar como mais um encorajamento ao projetista momentaneamente perder-se em meio as suas elaborações acerca das questões simbólicas do projeto e, assim, potencialmente evitar uma aderência excessiva às concepções, porventura superficiais, que podem ter se destacado em uma etapa primeira de análise da situação projetiva. Ao destinar esta atenção as suas próprias elaborações, escolhendo não se prender unicamente aos significantes que apareceram como centrais em um primeiro momento, o projetista pode vir a fazer articulações mais profundas e interligadas, e surpreender-se com relações ou proposições que não estavam evidentes em um 
primeiro momento. Assim, é possível desenvolver um trabalho de conceituação mais elaborado e substancial, aumentando o potencial de a materialidade do projeto de design operar ações significativas no mundo.

\section{Discussão e considerações finais}

O reconhecimento da relevância da dimensão simbólica e subjetiva no design aparece com mais ênfase na segunda metade do século XX. Desde então, o corpo teórico do design segue estreitando a relação do campo com a dimensão do simbólico. Em Beccari (2016), por exemplo, discute-se o entendimento de design enquanto um mediador da nossa relação com o real. Por meio das articulações simbólicas que permeiam os objetos de design, estes acabam por veicular nossas leituras e narrativas do real e, assim, sinalizam e reproduzem o ethos da época. Cardoso (2012) complementa esta visão, apontando para a transitoriedade das significações. Segundo o autor, "todo artefato material possui também uma dimensão imaterial de informação" (CARDOSO, 2012, p. 59), e esta dimensão imaterial se mantém em constante transformação. Nosso olhar e aquilo que depreendemos dos objetos são produtos de construção social e cultural e, assim, são determinados pela especificidade histórica do contexto.

No entanto, apesar de a centralidade da questão simbólica no design ser reconhecida em termos teóricos, esta questão parece ainda poder ser ampliada no que concerne à prática projetiva. Nas metodologias projetuais analisadas nesta pesquisa, identificou-se pouca profundidade nas diretrizes relativas ao manejo específico da dimensão simbólica do projeto. A prática da reflexão conceitual excessivamente diluída nos outros momentos do projeto pode apontar para um risco de pulverização desta etapa, incorrendo no eventual desenvolvimento de projetos com pouca substancialidade no âmbito da dimensão simbólica.

Nesse sentido, é possível se recorrer a outros campos do conhecimento, com o intuito de ampliar as discussões em torno da questão da conceituação nos projetos de design. Este é o caso da psicanálise, que devido à sua íntima relação com a dimensão simbólica, pode fomentar a discussão a respeito da conceituação e servir como impulso ao projetista/pesquisador que deseja pensar com mais cuidado o manejo dos aspectos simbólicos de projetos em design. A prática do psicanalista, que envolve uma escuta que busca se desprender das significações imediatas do discurso do analisando, pode ser benéfica ao designer na etapa de conceituação, encorajando-o a construir elaborações mais profundas e articuladas.

Dada a relevância da dimensão simbólica nos projetos de design e a escassez de investigações acerca da mesma no que concerne à prática projetiva, considera-se que essa pesquisa pode vir a impulsionar outras investigações sobre este tópico, com o objetivo de ampliar e aprofundar as discussões contemporâneas, e porventura possibilitar o aperfeiçoamento da prática, para que ela possa se tornar cada vez mais intencional e significativa. Vale destacar que as aproximações entre psicanálise e processos em design propostas por este estudo são apresentadas justamente com este objetivo, e não tanto com a pretensão de virem a ser tomadas como eventuais encaminhamentos metodológicos. O mundo contemporâneo, caracterizado por múltiplos discursos, excesso de estímulos, aceleração e aspectos da imaterialidade, possui desafios próprios, que pedem por investigações mais interligadas. Ao se realizar pesquisas e análises que buscam compreender a 
prática projetiva para além de uma excessiva objetivação e mecanização, espera-se contribuir para as perspectivas do design na contemporaneidade.

\section{Referências}

AMBROSE, Gavin; HARRIS, Paul. Design Thinking. Porto Alegre: Bookman, 2011. 200 p. (Coleção design básico).

BECCARI, Marcos. Articulações simbólicas: uma nova filosofia do design. Teresópolis: 2AB, 2016. 255 p.

BÜRDEK, Bernhard. Design - História, Teoria e Prática do Design de Produtos. São Paulo: Blucher, 2010. 496 p.

CARDOSO, Rafael. Design para um mundo complexo. São Paulo: Cosac Naify, 2012. 262 p.

COSTA, Joan. Imagem Global. Barcelona: Ediciones CEAC, 1989. 262 p.

DELEUZE, Gilles; GUATTARI, Félix. O que é a filosofia?. São Paulo: Editora 34, 1992. $279 \mathrm{p}$.

FERREIRA, Patrícia. Design conceptual na era pós-industrial: "a forma segue o conceito". 2010. 198 p. Dissertação (Mestrado em Design de produto) - Faculdade de Arquitectura, Universidade Técnica de Lisboa, Lisboa.

FRASCARA, Jorge. Diseño gráfico y comunicación. 7. ed. Buenos Aires: Ediciones Infinito, 2000. 127 p.

FREUD, Sigmund. O método psicanalítico freudiano (1904 [1905]). In: IANNINI, Gilson; TAVARES, Pedro Heliodoro (Orgs.). Fundamentos da clínica psicanalítica. Tradução de C. Dornbusch. 2. ed. Belo Horizonte: Autêntica, 2020. p. 51-61. (Obras incompletas de Sigmund Freud, v. 6).

Recomendações ao médico para o tratamento psicanalítico (1912). In: IANNINI, Gilson; TAVARES, Pedro Heliodoro (Orgs.). Fundamentos da clínica psicanalítica. Tradução de C. Dornbusch. 2. ed. Belo Horizonte: Autêntica, 2020. p. 93-106. (Obras incompletas de Sigmund Freud, v. 6).

HENRION, Frederick Henri Kay. La imagen corporativa. In: JONG, Cees. (Ed.), Manual de Identidad Corporativa. Barcelona: Gustavo Gili. 1991. p 41-47.

LONGO, Leila. Linguagem e psicanálise. Rio de Janeiro: Zahar, 2006. 76 p.

MOURA, Catarina. A palavra Design. Eikon - Journal on Semiotics and Culture, Covilhã, n. 5, p. 63-68, 2019.

PEÓN, Maria Luísa. Sistemas de identidade visual. 3. ed. Rio de Janeiro: 2AB. 2003. 100 p.

SOLER, Colette. O inconsciente: o que é isso?. 2. ed. São Paulo: Zagodoni, 2020. 160 p.

ZIMMERMANN, Yves. Del Diseño. Barcelona: Editorial Gustavo Gili, 1998. 169 p.

\section{Sobre as autoras}

\section{Luiza Fernandes Lootens Machado}

Psicóloga graduada pela Universidade de Brasília (UnB). Iniciou seus estudos em Design no Montgomery College, Estados Unidos, e é atualmente aluna de graduação de Design - 
Programação Visual, pela UnB. Interessa-se pela intersecção entre práticas criativas e psicanálise e trabalha, sobretudo, com Identidade Visual.

ORCID https://orcid.org/0000-0002-8225-1457

\section{Ana Mansur de Oliveira}

Professora Adjunta II do Departamento da Universidade de Brasília. Doutora em Teoria e Experimentações da Arte pela UFRJ, é docente colaboradora do Programa de Pós Graduação em Design da UnB. Tem mestrado em Design pela PUC-Rio e é especialista em Tipografia pelo London College of Printing, Inglaterra. Desenvolve pesquisas sobre investigações filosóficas de práticas criadoras contemporâneas, analisando os diálogos possíveis entre Arte e Design como propulsores para geração de inovação.

ORCID https://orcid.org/0000-0003-0301-3555 